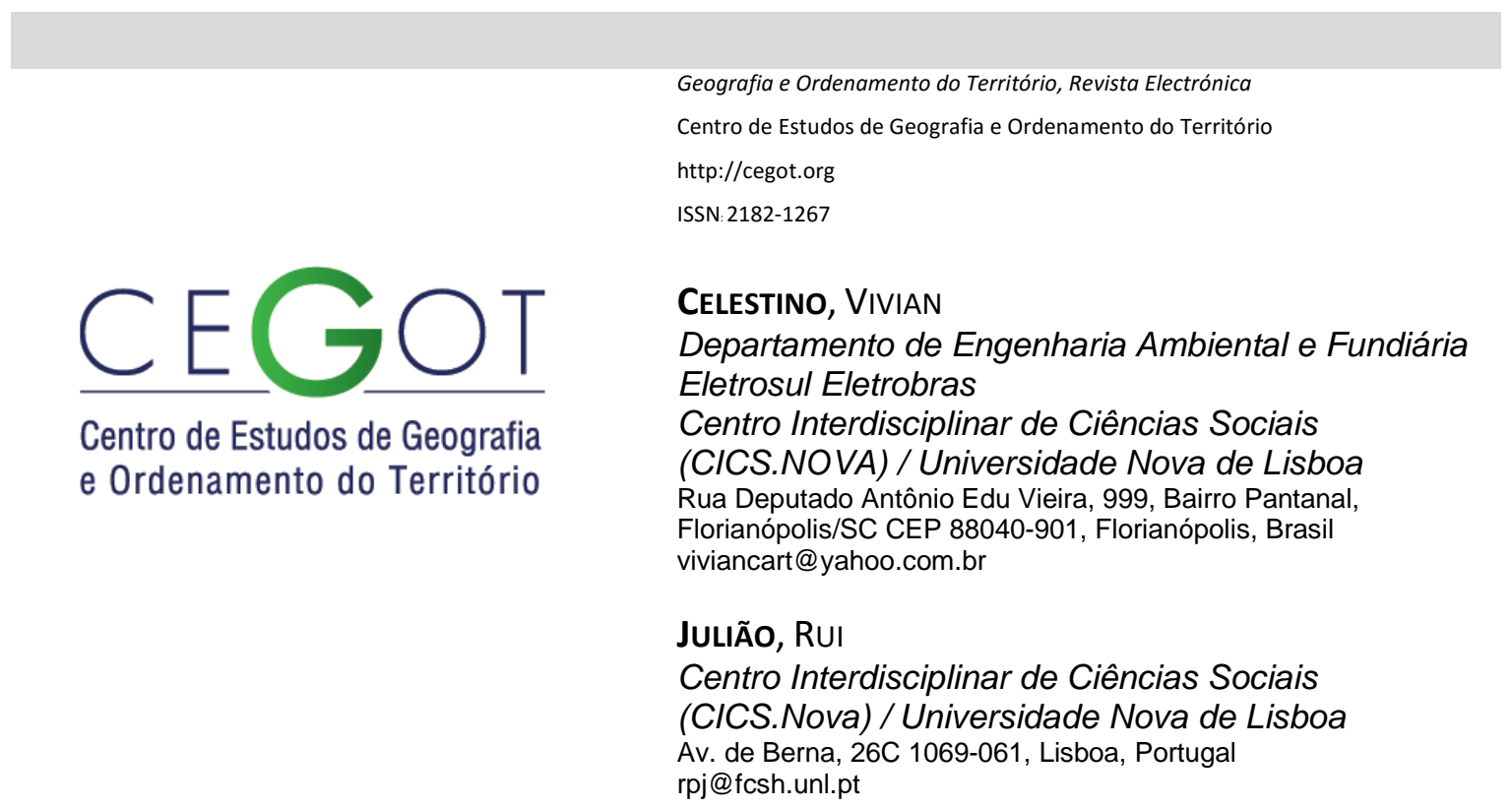

\title{
Modelagem conceitual para identificação de áreas com potencial para geração de energia por fonte renovável
}

\author{
Conceptual modeling to identify areas with potential for energy generation by \\ renewable source
}

Referência: Celestino, Vivian; Julião, Rui. (2016). Modelagem conceitual para identificação de áreas com potencial para geração de energia por fonte renovável. Revista de Geografia e Ordenamento do Território (GOT), n.o 9 (junho). Centro de Estudos de Geografia e Ordenamento do Território, p. 65-89, dx.doi.org/10.17127/got/2016.9.004

\section{RESUMO}

O mundo enfrenta um desafio na busca de alternativas para atender a demanda de energia elétrica de forma sustentável e diminuir os efeitos dos Gases de Efeito Estufa. Uma maneira de minimizar estes efeitos e expandir o parque gerador é incrementar a produção com recurso a fontes renováveis. Mas para que, no momento de instalar um novo empreendimento, seja tomada uma decisão assertiva é necessário realizar a compilação de variáveis que sejam pertinentes ao tema e ao espaço geográfico. O objetivo deste artigo é apresentar uma modelagem conceitual por objetos (de acordo com o padrão OMT-G) de forma a identificar áreas potenciais para gerar energia elétrica por fontes renováveis.

Palavras-chave: energias renováveis, Sistema de Informação Geográfica (SIG), modelagem conceitual, OMT-G.

\section{ABSTRACT}

The world faces a challenge in finding alternatives to meet the electricity demand in a sustainable way and reduce the greenhouse gases effects. A way to minimize these effects and expand the generating capacity is to increase production using renewable sources. But 
to make an assertive decision when installing a new power plant it is necessary to compile a set of variables that are relevant to the business and geographic space. The objective of this paper is to present an object conceptual model (according to the OMT-G standard) to identify potential areas for generating electricity from renewable sources.

Keywords: renewable energy, Geographic Information System (GIS), conceptual modeling, OMT-G.

\section{Introdução}

O mundo em que vivemos enfrenta um desafio ambiental, pois até o final do século XXI as temperaturas aumentarão em média $2^{0}$ Celsius se não forem tomadas medidas emergenciais para reduzir os gases de efeito estufa (GEE). Em contrapartida a atual crise energética tem demonstrado que não somente a fonte de geração hídrica é suficiente para atender a demanda de energia elétrica existente no mundo.

A água é o recurso natural mais abundante na Terra e é uma das poucas fontes para produção de energia que não contribui para o aquecimento global. Mas mesmo sendo considerada renovável a participação da água na matriz energética mundial é pouco expressiva (ANEEL, 2008).

Segundo o relatório Key World Energy Statistics (IEA, 2009), entre 1973 e 2006, a participação da força das águas na produção total de energia diminuiu de 2,2\% para apenas 1,8\%. No mesmo período, a posição na matriz da energia elétrica sofreu recuo acentuado: de $21 \%$ para $16 \%$, inferior à do carvão e à do gás natural. Vários elementos explicam esse aparente paradoxo. Um deles relaciona-se às características de distribuição da água na superfície terrestre. Do volume total, a quase totalidade está nos oceanos e, embora pesquisas estejam sendo realizadas, a força das marés não é utilizada em escala comercial para a produção de energia elétrica. Da água doce restante, apenas aquela que flui por aproveitamentos com acentuados desníveis e/ou grande vazão pode ser utilizada nas usinas hidrelétricas.

A redução da fonte hídrica na participação na matriz da energia elétrica tem também a ver com o esgotamento das reservas. Nos últimos 30 anos, também de acordo com levantamentos da IEA (2009), a oferta de energia hidrelétrica aumentou em apenas dois locais do mundo: Ásia, em particular na China, e América Latina, em função do Brasil, país 
em que a hidroeletricidade responde pela maior parte da produção da energia elétrica. Nesse mesmo período, os países desenvolvidos já haviam explorado todos os seus potenciais, o que fez com que o volume produzido registrasse evolução inferior ao de outras fontes, como gás natural e as usinas nucleares.

De acordo com o estudo sobre hidroeletricidade do Plano Nacional de Energia 2030, elaborado pela Empresa de Pesquisa Energética (EPE), do Brasil, são notáveis as taxas de aproveitamento da França, Alemanha, Japão, Noruega, Estados Unidos e Suécia, em contraste com as baixas taxas observadas em países da África, Ásia e América do Sul. Mesmo nessas últimas regiões, a expansão não ocorreu na velocidade prevista. Entre outros fatores, o andamento de alguns empreendimentos foi afetado pela pressão de caráter ambiental contra as usinas hidrelétricas de grande porte. O principal argumento contrário à construção das hidrelétricas é o impacto provocado sobre o modo de vida da população, flora e fauna locais, formação de grandes lagos ou reservatórios, aumento do nível dos rios ou alterações em seu curso após o represamento (ANEEL, 2008).

Fontes renováveis de energia têm sido pesquisadas por diferentes áreas com objetivo de buscar alternativas para atender a demanda de energia elétrica de forma sustentável, pois a combustão de energias fósseis (petróleo, gás e carvão) são responsáveis por dois terços das emissões mundiais dos GEE, seguida da deflorestação com $17 \%$ e a agricultura por $15,5 \%$.

No Protocolo de Kyoto de 1997 foi acordada a redução das emissões das principais substâncias responsáveis pelo aquecimento da atmosfera aos 36 países industrializados que o ratificaram, bem como os países com economias em transição. O protocolo impôs "objetivos diferenciados" de acordo com os países como, por exemplo, de $8 \%$ para o conjunto da União Européia, ou de 6\% para o Canadá e o Japão. Os países emergentes, dentre eles a China (que se converterá no principal contaminante mundial), Índia ou Brasil, estão exonerados das reduções, do mesmo modo que os países em desenvolvimento, apesar de seu crescimento excepcional (ONUDI, 2013).

Unindo as vertentes da redução dos GEE e a geração de energia, a União Europeia (UE) elaborou a iniciativa 20-20-20, que consiste em um programa onde os países da Europa têm os objetivos de elevar o peso das energias renováveis em $20 \%$ no consumo final, reduzir as emissões de dióxido de carbono em 20 \% (em relação a 1990) e aumentar a eficiência energética em $20 \%$, visando atingi-los de diferentes modos e em diversos horizontes de longo prazo. 
Neste sentido, a Presidência Portuguesa, exercida no segundo semestre de 2007, produziu um documento que desenvolveu a noção de "uma nova ERA para a energia", baseada na Eficiência, Renováveis (e produção geotermal limpa) e Avançados desenvolvimentos de rede e infraestruturas de armazenamento (ELOY, 2009). Este documento estratégico apontou para uma completa mudança de paradigma no setor energético, os objetivos eram claros "máxima eficiência e emissões mínimas!", onde os três pilares tecnológicos no acrônimo ERA são: utilização final eficiente, renováveis para a produção, e sistemas de rede de armazenamento inovadores, o que requer incentivos para a implementação e esforços de Investigação e Desenvolvimento.

\section{Justificativa}

Portugal é um país com enormes oportunidades ao nível das energias renováveis, pois possui um território rico em cadeias montanhosas para produção de energia hídrica e uma grande rede de barragens, localizadas no norte, que podem interagir com os aerogeradores eólicos que estão igualmente localizados, sobretudo a norte, em lógicas de armazenamento de energia em barragens (reversibilidade da água). Em relação à energia solar, Portugal é um dos países da Europa com maior disponibilidade de radiação solar devido à sua localização geográfica, com um número médio anual de horas de Sol entre 2.200 e 3.000 e, em relação ao solar fotovoltaico possui alto potencial na região do Alentejo (ELOY, 2009). É considerável também o potencial da energia de biomassa, em particular a que resulta da conversão de resíduos orgânicos, bem como a energia dos oceanos, devido a extensa costa litorânea.

Para que seja tomada uma decisão assertiva no momento de instalar um novo empreendimento de geração de energia por fontes renováveis, é necessário realizar a compilação de variáveis que sejam pertinentes ao tema relacionado à expansão da geração, ou seja, referentes à disposição do mercado e à comercialização de energia, vinculados a dados e informações distribuídas de forma espacial e sistêmica.

Um sistema pode ser definido como um conjunto ou arranjo de elementos relacionados de tal maneira a formar uma unidade ou um todo organizado e, no sentido da compilação organizada de variáveis de forma a permitir uma posterior análise, o conceito de Sistema de Informação (SI) surge como sendo um conjunto de componentes inter-relacionados que 
recolhem, processam, armazenam e distribuem informação para suportar a tomada de decisão e o controle de uma organização (MENDES, 2013).

Levando em consideração que os dados são a matéria-prima utilizada para produzir informação, um processo de decisão termina quando o recurso se torna disponível como um conhecimento para o utilizador interpretar a informação e tomar a decisão. Quando a informação produzida necessita ser espacializada geograficamente como um conhecimento para permitir a tomada de decisão, o conceito de Sistemas de Informação Geográfica (SIG) surge como uma solução.

De acordo com o Department of the Environment (DoE), os SIG são um sistema para capturar, armazenar, verificar, manipular, analisar e mostrar a informação que está espacialmente referenciada na Terra (MENDES, 2013). Pode ser considerado ainda como um conjunto/sistema de hardware, software e procedimentos concebidos para apoiar o recolhimento, a gestão, a análise, a modelação e a visualização de dados georreferenciados para solucionar problemas de planejamento e de gestão (MENDES, 2013).

A modelagem para identificação de áreas potenciais para geração de energia elétrica por fontes renováveis tem como objetivo principal preparar as informações necessárias a serem aplicadas em um determinado cenário a fim de identificar geograficamente a viabilidade de determinado projeto a priori. Neste ínterim o objetivo desta pesquisa é desenvolver um modelo conceitual a ser utilizado em SIG vinculando diferentes variáveis convencionais e geográficas, de forma a apoiar os processos decisórios que envolvam a expansão de parques geradores.

É urgente e necessária a utilização de SIG para facilitar a tomada de decisão, decorrente do grande número de dados e informações disponíveis que devem ser consideradas na hora de implantar um novo empreendimento de geração de energia. A utilização de SIG, por associar variáveis qualitativas e quantitativas, garante um resultado de qualidade, com menor custo associado e em menor tempo.

\section{Conceituação Teórica}

Neste capítulo serão apresentados os conceitos referentes ao tema do artigo, bem como a apresentação dos softwares utilizados. 


\subsection{Energia Hidrelétrica}

A energia hidrelétrica é gerada pelo aproveitamento do fluxo das águas em uma usina na qual as obras civis - que envolvem tanto a construção quanto o desvio do rio e a formação do reservatório - são tão ou mais importantes que os equipamentos instalados. As principais variáveis utilizadas na classificação de uma usina hidrelétrica são: altura da queda de água, vazão, capacidade ou potência instalada, tipo de turbina empregada, localização, tipo de barragem e reservatório. Todos são fatores interdependentes. Assim, a altura da queda de água e a vazão dependem do local de construção e irá determinar qual será a capacidade instalada que, por sua vez, determina o tipo de turbina, barragem e reservatório (ANEEL, 2008).

Existem dois tipos de reservatórios: acumulação e fio de água. Os primeiros, geralmente localizados na cabeceira dos rios, em locais de altas quedas de água, dado o seu grande porte, permitem o acúmulo de grande quantidade de água e funcionam como estoques a serem utilizados em períodos de estiagem. As unidades a fio de água geram energia com o fluxo de água do rio, ou seja, pela vazão com mínimo ou nenhum acúmulo do recurso hídrico (ANEEL, 2008).

O Centro Nacional de Referência em Pequenas Centrais Hidrelétricas (CERPCH) da Universidade Federal de Itajubá (UNIFEI) considera baixa queda uma altura de até 15 metros e alta queda uma superior a 150 metros. Mas não há consenso com relação a essas medidas.

Em grande escala a fonte de energia hídrica tem um campo de expansão limitado devido a aspectos de caráter financeiro, ambiental e social. Em pequena escala (na maior parte dos países com uma potencia instalada menor ou igual a $10 \mathrm{MW}$ ), a geração hidrelétrica com pequenas usinas oferece possibilidades de crescimento, em razão da diversidade de vazões que ainda são suscetíveis de aproveitamento (ONUDI, 2013) e existem inúmeras vantagens que são compartilhadas entre as pequenas e grandes usinas hidrelétricas, designadamente:

- Constitui uma fonte de energia renovável;

- É uma tecnologia madura, consolidada e com alto nível de confiança e rendimento;

- Os custos da energia gerada são praticamente independentes dos efeitos inflacionários;

- Constituem uma fonte de energia autóctone e, portanto, seu aproveitamento reduz a vulnerabilidade energética do país com relação aos mercados internacionais de combustíveis fósseis;

- Seus custos de operação e manutenção são relativamente baixos; 
- Têm uma vida relativamente longa;

- Possui um alto grau de disponibilidade operativa.

A princípios do século XX ocorreu uma intensa construção de pequenas usinas hidrelétricas na América do Norte, Europa e Ásia (JUANA, 2003). Nos anos 1920, a energia hidrelétrica gerada constituía $40 \%$ do total produzido mundialmente pelas usinas em seu conjunto. Depois, durante um longo período (50 anos), houve uma queda na construção de pequenas usinas hidrelétricas, dando lugar às grandes usinas hidráulicas que possuíam um maior rendimento econômico. Durante a década dos 70, em muitos países desenvolvidos e em vias de desenvolvimento, devido à crise energética mundial, as usinas hidrelétricas de pequena potência atraíram novamente a atenção dos empreendedores.

As pequenas usinas hidrelétricas podem ser classificadas por distintos parâmetros tais como potência, altura de carga e regime de trabalho, dentre outros. Na grande maioria dos países toma-se como base a potência instalada em kilo Watt (kW) ou Mega Watt (MW). Em alguns países consideram-se pequenas usinas hidrelétricas aquelas com um potencial de até 2.000 kW (Itália, Noruega, Suécia e Suíça) ou até 5.000 kW (Áustria, Índia, França, Canadá, Alemanha e outros).

A Organização das Nações Unidas para o Desenvolvimento Industrial (ONUDI) tipifica como pequenas usinas hidrelétricas as que possuam uma potência instalada de até $5.000 \mathrm{~kW}$. Em outros países, esta potência é de até 30.000 kW, como nos Estados Unidos, Brasil e no CEI (antiga Rússia). Já a Organização Latino-americana de Desenvolvimento de Energia (OLADE) considera como pequena usina as que possuem uma potencia entre 1.000 e $10.000 \mathrm{~kW}$.

No Brasil a potência instalada determina se a usina é de grande ou médio porte ou uma Pequena Central Hidrelétrica (PCH). A Agência Nacional de Energia Elétrica (ANEEL) do Brasil adota três classificações: Centrais Geradoras Hidrelétricas (com até $1 \mathrm{MW}$ de potência instalada), Pequenas Centrais Hidrelétricas (PCH) (entre 1,1 MW e $30 \mathrm{MW}$ de potência instalada) e Usina Hidrelétrica de Energia (UHE, com mais de $30 \mathrm{MW}$ ). Para ser considerada uma $\mathrm{PCH}$ também deve ser considerada uma área alagada de até $1,3 \mathrm{~km}^{2}$ e uma altura de queda até $10 \mathrm{~m}$ de altura.

\subsection{Energia Eólica}

A energia eólica é, basicamente, aquela obtida da energia cinética (do movimento) gerada pela migração das massas de ar provocada pelas diferenças de temperatura existentes na 
superfície do planeta. A geração eólica ocorre pelo contato do vento com as pás do catavento, elementos integrantes da usina. Ao girar, essas pás dão origem à energia mecânica que aciona o rotor do aerogerador e produz a eletricidade. A quantidade de energia mecânica transferida - e, portanto, o potencial de energia elétrica a ser produzido está diretamente relacionado à densidade do ar, à área coberta pela rotação das pás e à velocidade do vento. A evolução da tecnologia permitiu o desenvolvimento de equipamentos mais potentes. No entanto, a densidade do ar, a intensidade, direção e velocidade do vento relacionam-se a aspectos geográficos naturais como relevo, vegetação e interações térmicas entre a superfície da terra e a atmosfera. Assim, a exemplo do que ocorre com outras fontes, como a hídrica, a obtenção da energia eólica também pressupõe a existência de condições naturais específicas e favoráveis. A avaliação destas condições ou do potencial eólico de determinada região - requer trabalhos sistemáticos de coleta e análise de dados sobre a velocidade e o regime dos ventos (ANEEL, 2008).

Nas últimas décadas ocorreu um desenvolvimento vertiginoso de grandes instalações eólicas conectadas à rede elétrica convencional, denominadas normalmente parques eólicos, e atualmente dedica-se muito esforço na implantação de instalações semelhantes no mar (eólica offshore) (ONUDI, 2013).

A energia dos ventos é considerada uma fonte renovável, amplamente disponível, limpa e com baixo impacto ambiental, principalmente por não emitir resíduos como gás carbônico. Os países que mais fazem uso dessa energia são a Alemanha, Estados Unidos, Espanha, Índia, China, Dinamarca, Itália, França, Reino Unido e Portugal (AMARANTE, 2009).

Normalmente as zonas mais ventosas são as terras altas e as grandes áreas livres sem barreiras. Com a tecnologia atual, a instalação de uma turbina tem interesse caso o local esteja sujeito a apenas ventos com velocidade média anual superior a 3,6 $\mathrm{m} / \mathrm{s}$, persistentes e regulares e com baixas intensidades de turbulência (ELOY, 2009).

\subsection{Energia Solar}

O Sol é um enorme reator de fusão nuclear formado por uma esfera de matéria gasosa quente de 1,39 milhões de quilômetros de diâmetro, que constitui a principal fonte de energia para a Terra, situada a uma distância média de 149.610,80 km. Devido à radiação solar, a temperatura na superfície terrestre é cerca de $250^{\circ} \mathrm{C}$ superior à temperatura que existiria na superfície se esta dependesse somente do calor interno (ONUDI, 2013). 
A energia solar recebida na atmosfera exterior da Terra em um ano se conhece como SERPE (Solar Energy Received Per Year) e corresponde a 1,55*10 $15 \mathrm{MWh}$, quantidade que equivale aproximadamente a 12.000 vezes a energia consumida no mundo, considerando os dados publicados de produção e consumo energético mundial durante o ano 2005 (BRITISH PETROLEUM, 2006). Da radiação recebida na superfície exterior, 30\% é refletida ao espaço, $47 \%$ é absorvido pela atmosfera, mares e Terra para manter a temperatura ambiente, e o restante $23 \%$ se usa para manter a convecção atmosférica e o ciclo hidrológico.

A energia solar chega à Terra nas formas térmica e luminosa. Essa radiação, porém, não atinge de maneira uniforme toda a crosta terrestre. Depende da latitude, da estação do ano e de condições atmosféricas como nebulosidade e umidade relativa do ar. Ao passar pela atmosfera terrestre, a maior parte da energia solar manifesta-se sob a forma de luz visível de raios infravermelhos e de raios ultravioleta. É possível captar essa luz e transformá-la em alguma forma de energia utilizada pelo homem. São os equipamentos utilizados nessa captação que determinam qual será o tipo de energia a ser obtida. Se for utilizada uma superfície escura para a captação, a energia solar será transformada em calor. Se utilizadas células fotovoltaicas, o resultado será a eletricidade (ANEEL, 2008).

O ritmo de crescimento da potência fotovoltaica instalada nos últimos anos superou todas as previsões, demonstrando o potencial desta tecnologia como fonte de energia em todo o mundo. É importante mencionar que a maior parte da potência instalada corresponde às instalações conectadas à rede, contando com $98 \%$ da capacidade global, ainda que exista um recente interesse nas instalações isoladas e sistemas de pequena escala principalmente em áreas remotas de difícil acesso e em países em desenvolvimento (ONUDI, 2013).

Um sistema fotovoltaico não precisa do brilho do sol para operar. Ele também pode gerar eletricidade em dias nublados. Segundo a Renewable Energy Policy Network for the 21st Century (REN21), os sistemas fotovoltaicos conectados à rede continuaram a ser, em $2006 \mathrm{e}$ 2007, a tecnologia de geração com maior crescimento no mundo (ANEEL, 2008).

O avanço tecnológico que tornou possível o desenvolvimento da fonte fotovoltaica decorre da confluência de vários fatores: por um lado, a maturidade tecnológica de todos os componentes do sistema, unida ao crescimento da capacidade global de fabricação, aos programas de fomento de alguns países, especialmente europeus, e a outros fatores conjunturais como o alto preço do petróleo e a facilidade para conseguir financiamento para este tipo de tecnologia. Ademais, é interessante comprovar a evolução da fabricação 
de células solares no mundo, junto com sua distribuição geográfica. $O$ rápido crescimento fez com que novos mercados se desenvolvessem, até o ponto que, segundo dados de 2011, houvesse um domínio do mercado asiático com relação à fabricação de células, especialmente da China. Enquanto em 2006 o principal produtor de células era o Japão, com 37\% do total, e a Europa, com 28\%, em 2008 a China já produzia 32,7\% (uma de cada três células), e em 2011 chegava a 57\% (ONUDI, 2013). Tradicionalmente a tecnologia de silício cristalino foi, e continua sendo, a tecnologia dominante com relação à fabricação de módulos.

A energia solar apresenta-se cada vez mais como uma grande solução energética para o planeta, é uma fonte inesgotável, gratuíta e não poluente. Portugal dispõe de muitas horas de sol por ano, e está em situação privilegiada para a utilização desta energia (ELOY, 2009).

\subsection{Modelagem conceitual e o Modelo OMT-G}

Modelagem conceitual de dados geográficos é uma representação e organização simplificada de elementos da realidade geográfica com a finalidade de criar aplicações de banco de dados geográficos envolvendo a descrição de conteúdo, a estrutura e as operações. Um esquema conceitual pode descrever dois tipos de dados: gráficos (notações) e semânticos (nomes das classes, dos atributos, multiplicidades das associações, etc.) (HUBNER, 2009).

Segundo Lisboa Filho et al. (2000) entre os modelos conceituais para dados geográficos mais conhecidos estão os do formalismo orientado à objetos (OO), tais como: GeoOOA, MADS, OMT-G e UML-GeoFrame.

Lisboa Filho et al. (2000) destacam diversas vantagens da modelagem conceitual para aplicações geográficas, dentre elas: facilita a execução do projeto lógico; a modelagem conceitual independe do software no qual o sistema é implementado; facilita a troca de informações entre parceiros de diferentes organizações, uma vez que aumenta a capacidade de entendimento da semântica da informação, facilitando o uso correto da mesma.

As aplicações geográficas, dentre elas os SIG conferem alguns requisitos específicos de modelagem de dados, em função dos aspectos espaciais, temporais e descritivos da informação geográfica. Borges (1997) e Lisboa Filho e lochpe (1999b) apresentam um 
conjunto de requisitos mínimos que um modelo conceitual de dados para aplicações geográficas deve suportar:

- Diferenciar fenômenos geográficos e objetos sem referência espacial (objetos convencionais), assim como os relacionamentos entre eles;

- Modelar dados geográficos nas visões de campo e de objetos;

- Modelar as características espaciais dos dados;

- Representar tanto as relações espaciais (topológicas) e suas propriedades, como também as associações simples e de rede;

- Especificar restrições de integridade espacial;

- Organizar os fenômenos níveis de informação;

- Modelar as características temporais dos dados e seus relacionamentos;

- Modelar as múltiplas representações (ponto, linha ou polígono) de uma mesma entidade geográfica, tanto com base em variações de escala como de forma;

- Modelar a qualidade dos dados (metadados);

- Ser independente de implementação (software).

O Object Modeling Technique (OMT) é uma técnica de modelagem criada nos anos 80 para o formalismo orientado à objeto (CRAVEIRO, 2004) que acrescenta primitivas ao diagrama de classes da Unified Modeling Language (UML) para modelar a geometria e a topologia dos dados geográficos, oferecendo estruturas de agregação, especialização/generalização, rede, e de associações espaciais (BORGES, 2002).

O OMT-G tem como base três conceitos principais: classes, relacionamentos e restrições de integridade espaciais. A partir do diagrama de classes é possível emanar um conjunto de restrições de integridade espaciais, que deve ser considerado na fase de implementação do projeto de SIG (BORGES et al, 2005). Até o momento não existe uma ferramenta CASE específica para construção de esquemas no modelo OMT-G, somente uma extensão (Stencil) para o software proprietário Microsoft Visio 2000 desenvolvida por Borges (QUEIROZ e FERREIRA, 2006).

\subsubsection{Classes do Modelo OMT-G}

Segundo Borges (1997) um modelo OMT-G possui como tripé as classes, os relacionamentos e as restrições de integridades espaciais. As classes podem ser convencionais ou georreferenciadas. Cada uma destas possui subclasses e uma semiologia que as identifica. Estes dois tipos de classes representam os grupos de dados, que podem ser contínuos, discretos e não espaciais.

As classes convencionais possuem atributos e algum tipo de relação com um objeto espacial, mas não têm propriedades geométricas (Figuras 01a e 01b). Cada classe é 
representada por um retângulo, subdividido em linhas. Na parte superior é especificado o nome da classe, no meio são delineados os seus atributos e na parte inferior suas operações.

As classes georreferenciadas, além de possuírem as características das classes convencionais, detêm propriedades geométricas (Figuras 01c à 01n), as quais são representadas através de um símbolo apropriado na primeira linha do retângulo.

As classes georreferenciadas possuem subclasses do tipo Geo Campo e Geo Objeto. A classe Geo Campo é composta por entidades que possuem justaposição espacial, preenchendo por completo o espaço (Figuras 01e, 01g e 01j). Estas subclasses são: Rede Irregular Triangular, Isolinhas, Polígonos Adjacentes, Tesselação e Amostragem.

As classes de Geo Objetos preveem polígonos, pontos ou linhas para representar os dados (Figuras 01h, 01i e 01n).

\begin{tabular}{|l|}
\hline \multicolumn{1}{|c|}{ Nome da Classe } \\
\hline Atributos \\
\hline Operações \\
\hline
\end{tabular}

a) Convencional

\begin{tabular}{|l|c|}
\hline$\triangle$ & $\begin{array}{c}\text { Nome da } \\
\text { Classe }\end{array}$ \\
\hline Atributos \\
\hline Operações \\
\hline
\end{tabular}

e) TIN

\begin{tabular}{|l|c|}
\hline S & $\begin{array}{c}\text { Nome da } \\
\text { Classe }\end{array}$ \\
\hline Atributos \\
\hline Operações \\
\hline
\end{tabular}

i) Isolinha

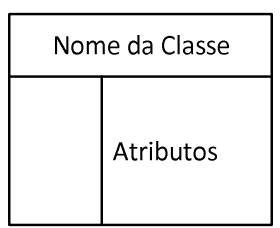

b) Apresentação

\begin{tabular}{|l|c|}
\hline$: 8$ & $\begin{array}{c}\text { Nome da } \\
\text { Classe }\end{array}$ \\
\hline Atributos \\
\hline \multicolumn{2}{|l|}{ Operações } \\
\hline
\end{tabular}

f) Amostragem

\begin{tabular}{|l|c|}
\hline 曲 & $\begin{array}{c}\text { Nome da } \\
\text { Classe }\end{array}$ \\
\hline Atributos \\
\hline Operações \\
\hline
\end{tabular}

j) Tesselação

\begin{tabular}{|l|c|}
\hline$\leftrightarrow$ & $\begin{array}{c}\text { Nome da } \\
\text { Classe }\end{array}$ \\
\hline Atributos \\
\hline Operações \\
\hline
\end{tabular}

m) Arco Bidirecional

\begin{tabular}{|l|c|}
\hline & $\begin{array}{c}\text { Nome da } \\
\text { Classe }\end{array}$ \\
\hline Atributos \\
\hline Operações \\
\hline
\end{tabular}

c) Georreferenciada Genérica

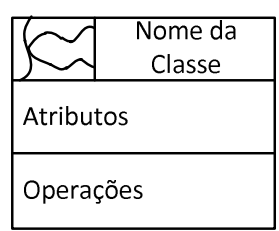

g) Polígonos Adjacentes

\begin{tabular}{|l|l|}
\hline 0 & $\begin{array}{c}\text { Nome da } \\
\text { Classe }\end{array}$ \\
\hline Atributos \\
\hline Operações \\
\hline
\end{tabular}

k) Nó

\begin{tabular}{|l|c|}
\hline$\hat{w}$ & $\begin{array}{c}\text { Nome da } \\
\text { Classe }\end{array}$ \\
\hline Atributos \\
\hline Operações \\
\hline
\end{tabular}

n) Ponto

\begin{tabular}{|l|c|}
\hline$\square$ & $\begin{array}{c}\text { Nome da } \\
\text { Classe }\end{array}$ \\
\hline Atributos \\
\hline Operações \\
\hline
\end{tabular}

d) Polígono

\begin{tabular}{|l|l|}
\hline Atributos & $\begin{array}{c}\text { Nome da } \\
\text { Classe }\end{array}$ \\
\hline Operações
\end{tabular}

h) Linha

\begin{tabular}{|l|l|}
\hline$\longrightarrow$ & $\begin{array}{c}\text { Nome da } \\
\text { Classe }\end{array}$ \\
\hline Atributos \\
\hline Operações \\
\hline
\end{tabular}

l) $\operatorname{Arco}$ Unidirecional

Figura 01 - Classes do Diagrama OMT-G 


\subsubsection{Relacionamentos (Associações) do Modelo OMT-G}

Um relacionamento é uma associação entre duas ou mais entidades. De acordo com Borges (1997) e (2001), o modelo OMT-G define três tipos diferentes de associações: associações simples, associações espaciais e associações topológicas em rede.

A associação simples representa o relacionamento entre objetos de duas classes distintas e são representadas por: uma linha que interliga as duas classes, o nome da ligação e uma seta em cima da linha, indicando a direção do relacionamento (Figura 02a).

A associação espacial é utilizada para definir a relação entre duas classes georreferenciadas, para representar uma relação topológica, métrica, de ordem ou fuzzy. Ela é representada por uma linha pontilhada interligando as duas classes e, da mesma maneira que a associação simples possui o nome e uma seta em cima da linha, indicando a direção do relacionamento entre as classes (Figura 02b).

A associação topológica em rede define o relacionamento entre dois objetos que estão interligados. Interligam os geo-objetos do tipo: linha unidirecional, linha bidirecional e nó de rede. São representadas por duas linhas pontilhadas ligando as classes ou ligando-se à mesma classe. Entre as linhas é descrito o nome da ligação (Figuras 02c e 02d).

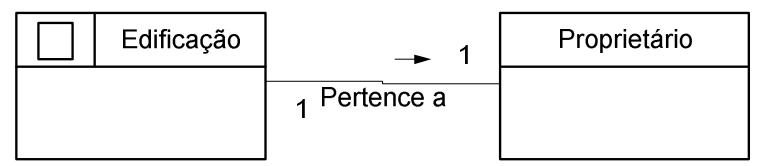

a) Associação Simples

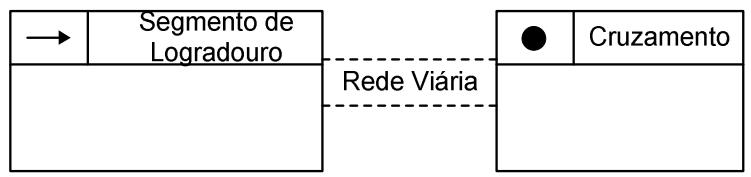

c) Relacionamento de Rede Arco - Nó

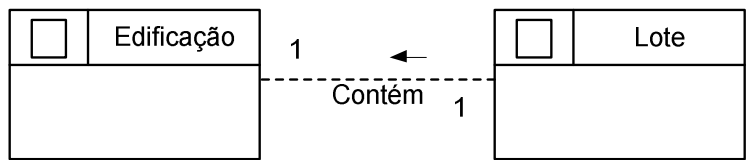

b) Associação Espacial

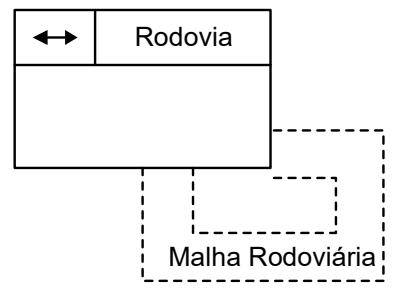

d) Relacionamento de Rede Arco - Arco

Figura 02 - Representação das associações do OMT-G

Fonte - Borges (1997)

Os relacionamentos são caracterizados por sua cardinalidade. A cardinalidade representa o número de instâncias de uma classe que podem estar associadas a instâncias da outra classe. É um tipo de restrição de integridade e aparece nos finais de cada linha, na forma "mínimo...máximo", onde mínimo e máximo são números inteiros, zero, um ou * (indicando mais de uma ocorrência). Ex: 0...* (zero ou mais), 1...* (um ou mais), 1 (exatamente um), 
0...1 (zero ou um). Quando não consta indicação de cardinalidade na associação, significa que os valores de mínimo e máximo equivalem a 1 (HUBNER, 2009).

\subsection{Software Windographer}

O software Windographer ${ }^{\circledR}$ é uma ferramenta utilizada para tratamento de dados coletados de estações meteorológicas de superfície donde é possível calcular a intensidade e a direção predominante dos ventos num determinado período e obter o perfil diário, mensal ou anual da sequência de dados. O software pode exibir diversos gráficos e tabelas como do perfil logarítmico do vento, direção, médias mensais e diárias. O software foi desenvolvido por Mistaya Engenharia INC e é disponibilizado gratuitamente uma versão de teste válida por um período entre 7 e 14 dias dependendo da versão (LINARD, 2010).

Com o Windographer ${ }^{\circledR}$ também é possível realizar a simulação de velocidades dos ventos em diversas alturas a partir de um pacote de dados medidos em uma única altura. O perfil logarítmico do vento pode ser calculado utilizando a fórmula do Perfil Logarítmico informando o parâmetro de rugosidade e também pode ser calculado utilizando a fórmula da Lei de Potência informando o expoente da lei de Potência. O mais comum é a simulação da velocidade sintetizada do vento na altura das torres anemométricas $(80 \mathrm{~m}, 100 \mathrm{~m}$ ou 150 m), para tanto necessita como input da inserção de dados coletados em variadas alturas de velocidade e direção do vento para este cálculo, combinadas das outras séries de dados como temperatura, umidade relativa do ar, pressão atmosférica e velocidade vertical.

O software solicita como dados de entrada as variáveis de: latitude, longitude, elevação, data de início, data de término, duração, intervalo de tempo, Calm threshold (limiar de calma), temperatura, pressão, umidade relativa do ar, velocidade de vento e direção do vento em diferentes alturas, velocidade vertical, rugosidade, entre outros. O software retorna como resultados relatórios em forma de gráficos ou tabelas, de acordo com a listagem do quadro 01.

\begin{tabular}{|c|c|}
\hline Gráfico & Descrição \\
\hline $\begin{array}{lll}\text { Perfil Vertical de } \\
\text { Vento }\end{array}$ & $\begin{array}{l}\text { Apresenta a velocidade média do vento em várias alturas, bem como o perfil } \\
\text { com a função logarítmica que melhor se ajusta a lei de potência. }\end{array}$ \\
\hline Rosas dos Ventos & Mostra a frequência com que o vento sopra em cada direção. \\
\hline $\begin{array}{l}\text { Perfil Mensal de } \\
\text { Velocidade de Vento }\end{array}$ & $\begin{array}{l}\text { Apresenta a velocidade média do vento em cada mês do ano para várias } \\
\text { alturas. Em conjuntos de dados abrangendo vários anos, as médias mensais } \\
\text { incluem valores de todos os anos. }\end{array}$ \\
\hline $\begin{array}{l}\text { Perfil Diurno de } \\
\text { Velocidade de Vento }\end{array}$ & $\begin{array}{l}\text { Apresenta a velocidade média do vento para cada hora do dia em várias } \\
\text { alturas. }\end{array}$ \\
\hline
\end{tabular}

Quadro 01 - Resultados Apresentados pelo Windographer

Fonte - AWS Truepower LLC (2015) 


\subsection{Model Builder}

O Model Builder é uma ferramenta de apoio essencial na operacionalização dos modelos conceituais. Trata-se de um instrumento que, muito mais do que permitir o desenho do modelo, testa o procedimento, validando-o e permitindo a sua operacionalização (COSME, 2012), podendo ser considerado uma ferramenta de programação gráfica que reúne funções de geoprocessamento e permite a elaboração de modelos (processos) que podem ser utilizados em múltiplas ocasiões.

O seu uso é vantajoso, pois permite visualizar graficamente a separação dos processos, os fluxos de informação e seu processamento. Possui ainda como vantagem a utilização de múltiplos contextos, desde a análise multicritério à simulação e parametrização de cenários (COSME, 2012), bem como a não utilização de códigos para gerar os processos e a execução de novos modelos a qualquer momento a partir de uma predefinição (modificação de parâmetros) para produção de novos resultados.

O Model Builder é um componente do software ArcGIS que permite a criação de modelos (representação simplificada e gerenciável da realidade) a partir de fluxos que unem uma sequência de ferramentas necessariamente presentes no ArcToolbox e base de dados e, permite tanto criar fluxos de rotina de trabalho quanto novas ferramentas (SILVA, 2015).

\section{Método}

Para desenvolver o método proposto primeiramente foi necessário realizar pesquisas em diferentes fontes bibliográficas e definir quais as matrizes de energia elétrica (por fontes renováveis) seriam utilizadas, levando em consideração as necessidades mundiais, bem como os recursos naturais ainda disponíveis.

A partir da definição das matrizes o segundo passo foi identificar que materiais e/ou produtos convencionais e cartográficos primários são considerados fundamentais para gerar informações secundárias, bem como se são disponibilizados de forma gratuíta e virtual.

A partir deste ponto foram definidos o padrão de linguagem necessário para realizar a modelagem conceitual e seu respectivo software/aplicativo.

Após a etapa de definição foi desenvolvido um diagrama de classes que descreveu e fixou as regras de forma conceitual para a estrutura construída, através da realização da análise do 
comportamento dos atributos das variáveis geográficas e convencionais do mundo real e a sua representação na forma de classes de objetos e seus respectivos relacionamentos.

Para a produção da etapa de descrição de operações foi necessário também definir quais softwares seriam necessários caso a implementação fosse realizada. Para modelagens eólicas é sempre necessário modelar as informações antes de inserí-las em um SIG. Também foi necessário definir um software para modelar as operações relativas ao SIG, propriamente dita.

Após as etapas de definições foi gerado um diagrama de classes que consistiu em uma estrutura de classes. Tal estrutura visou à determinação de áreas com potencial para geração de energia elétrica, primeiro de forma isolada, ou seja, foram definidos fluxos para as diferentes fontes estudadas, com classes e relacionamentos comuns a dois ou três tipos delas, donde resultaram, através de operações, classes indicativas do potencial isolado por fonte geradora.

A classe resultante deste diagrama, gerada através de relacionamentos no final do diagrama indica espacialmente áreas em comum com potencial para geração de energia por até três fontes renováveis. O fluxograma do método proposto está sendo apresentado na figura 03.

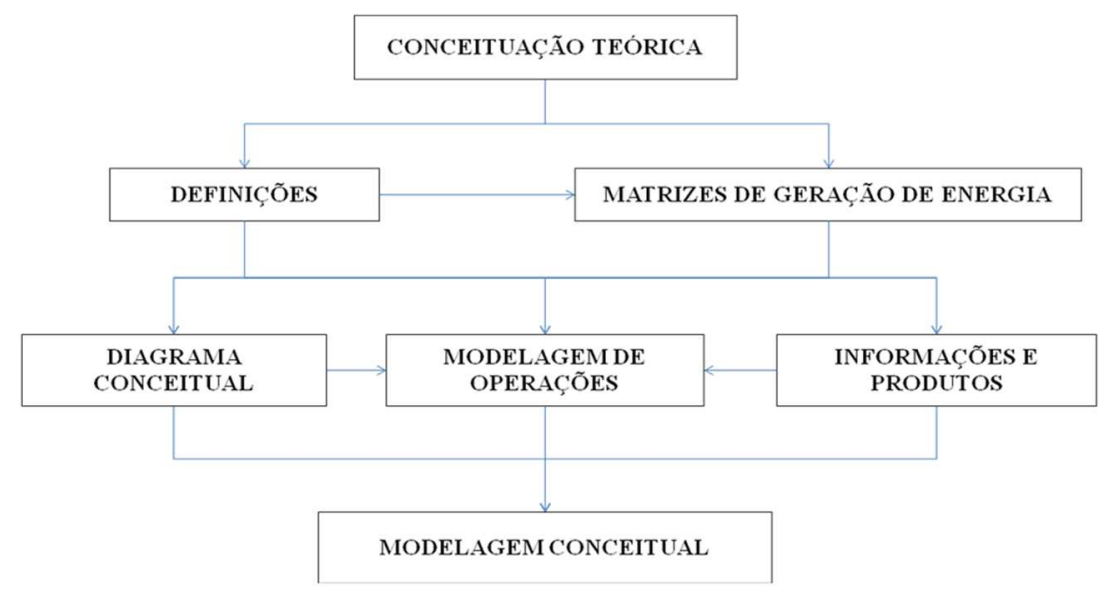

Figura 03 - Método Proposto

\section{Resultados}

Neste capítulo serão apresentados os resultados obtidos na pesquisa, conforme método apresentado no capítulo 4.

Como o ramo de produção de energia elétrica por fontes renováveis está sendo explorado em todo o mundo e com base em toda a revisão de literatura apresentada no capítulo 03, as 
matrizes de energia renováveis definidas para produção desta modelagem foram: hídrica de pequeno formato (com altura de queda de $10 \mathrm{~m}$ de alura e barramento de 150 metros), eólica e solar (térmico e fotovoltaico).

Não somente as fontes, mas principalmente a definição de informações e produtos cartográficos/meteorológicos primários advindos do mundo real foram imprescindíveis para modelar o fluxo de mapeamento e a respectiva geração de informação secundária necessária para identificar no final as áreas com potencial para gerar energia elétrica pelas fontes renováveis definidas.

Em toda literatura estudada são fundamentais para qualquer das três fontes definidas, seja hídrica, solar ou eólica, que sejam utilizados modelos digitais de elevação (MDE), donde possam ser derivadas as informações de altura, inclinação/declividade e aspecto da superfície mapeada. Também são necessárias informações a respeito do uso e ocupação do solo, que podem ser advindas de classificações de imagens de satélite ou de mapeamentos temáticos, para definir as restrições que devem ser levadas em consideração no mapeamento de potencial energético. Essenciais somente para o mapeamento de potencial eólico são os dados meteorológicos advindos de estações meterorológicas para gerar as informações de intensidade/velocidade de vento sintetizada em softwares específicos.

Para produção do diagrama de classes foi necessário, primeiramente, abstrair do mundo real os dados, informações e produtos cartográficos (necessários ao mapeamento das matrizes definidas) para o conceitual em classes (convencionais e georreferenciadas) imprescindíveis para atingir ao objetivo proposto. Os níveis e as classes definidas estão sendo apresentadas no quadro 02.

\begin{tabular}{|l|l|}
\hline \multicolumn{1}{|c|}{ Níveis de Informações (Universo Real) } & Classes (Universo Conceitual) \\
\hline MDE advindo de SRTM (Space Shuttle Topography Mission) & $\begin{array}{l}\text { Classe Georreferenciada } \\
\text { (Tesselação) }\end{array}$ \\
\hline $\begin{array}{l}\text { Imagens de Satélite destinadas à classificação supervisionada } \\
\text { para mapeamento de uso e/ou ocupação de solo }\end{array}$ & $\begin{array}{l}\text { Classe Georreferenciada } \\
\text { (Tesselação) }\end{array}$ \\
\hline Estação Meteorológica & $\begin{array}{l}\text { Classe Georreferenciada } \\
\text { (Ponto) }\end{array}$ \\
\hline $\begin{array}{l}\text { Dados meteorológicos: Direção e Velocidade de Vento } \\
\text { captados em três alturas diferentes, Velocidade Vertical de } \\
\text { Vento, Umidade Relativa, Pressão Atmosférica e Temperatura }\end{array}$ & Classe Convencional \\
\hline
\end{tabular}

Quadro 02 - Níveis de Informações e Classes

O diagrama de classes produzido neste trabalho seguiu os padrões, conceitos e semiologia necessários a uma modelagem conceitual dentro dos parâmetros e estereótipos do modelo 
OMT-G apresentados no item 3.4. Para desenhá-lo foi utilizado o Stencil OMT-G no Microsoft Visio 2010.

Primeiramente foram identificados os objetos geográficos e convencionais que compuseram o tema e os mesmos foram agrupados em classes. O diagrama foi utilizado para agregar objetos de mesmas características, atributos e comportamentos e também para auxiliar a visualização dos níveis de informação. Como resultado para o Modelo Conceitual obteve-se o total de 36 classes, sendo 34 geográficas e 2 convencionais. As classes convencionais utilizadas estão sendo apresentadas na figura 04.

\begin{tabular}{|c|}
\hline Dados Meteorológicos \\
\hline $\begin{array}{l}\text { Direção Vento } \times 1: \text { Float (graus decimais) } \\
\text { Direção Vento } \times 2 \text { : Float (graus decimais) } \\
\text { Direção Vento } \times 3 \text { : Float (graus decimais) } \\
\text { Velocidade Vento } \times 1 \text { : Float (m/s) } \\
\text { Velocidade Vento } \times 2 \text { : Float }(\mathrm{m} / \mathrm{s}) \\
\text { Velocidade Vento } \times 3 \text { : Float }(\mathrm{m} / \mathrm{s}) \\
\text { Velocidade Vertical } \times 1: \text { Float }(\mathrm{m} / \mathrm{s}) \\
\text { Umidade Relativa } \times 1: \text { Float }(\%) \\
\text { Pressão Atmosférica } \times 1: \text { Float }(\mathrm{hPa}) \\
\text { Temperatura } \times 1: \text { Float }\left({ }^{\circ} \mathrm{C}\right)\end{array}$ \\
\hline Tabular dados meteorológicos \\
\hline
\end{tabular}

\begin{tabular}{|l|}
\hline \multicolumn{1}{|c|}{ Altitude Lâmina } \\
\hline Value: Float $(\mathrm{m})$ \\
\hline Inserir Altitude \\
\hline
\end{tabular}

Figura 04 - Classes convencionais utilizadas

As classes de fenômenos geográficos receberam representação conceitual conforme a visão de campos e objetos com as primitivas geométricas de ponto e tesselação (as demais primitivas descritas no OMT-G não foram utilizadas), sendo que somente duas classes apresentaram a feição "Ponto". Ver o símbolo do canto superior esquerdo das classes apresentadas na figura 05, com representação análoga às informações advinda dos níveis de informação "Estação Meteorológica" e "Velocidade de Vento Sintetizada".
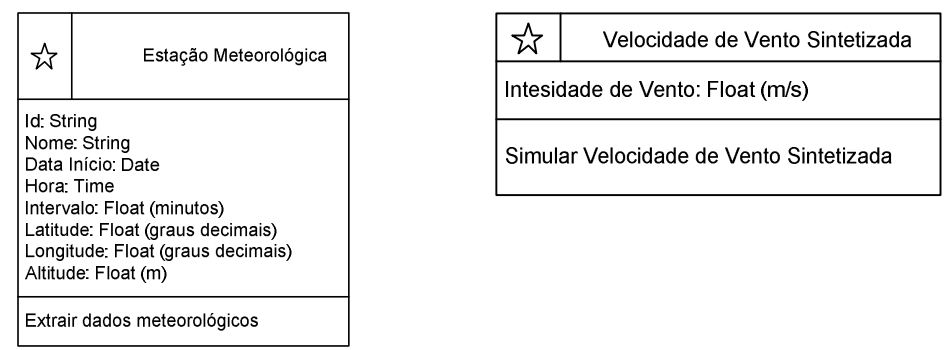

Figura 05 - Classes geográficas com a primitiva "Ponto"

Estão sendo apresentadas, na figura 06, como exemplo, duas classes com representação da primitiva "Tesselação", muito utilizada no modelo, relativas aos níveis de informações "Imagem Radar" e "Imagem Satélite". 


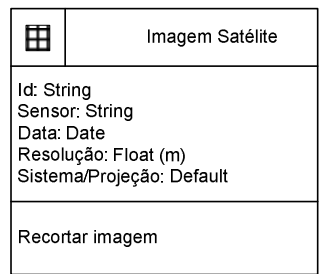

\begin{tabular}{|l|l|}
\hline 曲 & \multicolumn{1}{|c|}{ Imagem Radar } \\
\hline Id: String \\
Fonte: String \\
Data: Date \\
Satelite: String \\
Resolução: Float $(\mathrm{m})$ \\
Altitude: Float $(\mathrm{m})$ \\
\hline Recortar imagem \\
\hline
\end{tabular}

Figura 06 - Exemplo de classes geográficas com a primitiva "Tesselação" utilizadas

Após a etapa de representação conceitual das classes de objetos foi realizada a modelagem dos atributos espaciais e convencionais de cada classe, onde foram atribuídos domínios para os tipos de dados de acordo com suas características de armazenamento em meio computacional: String (Alfanumérico), Boolean, Float (Decimal) e Date. Ver detalhes nas figuras 05 e 06, onde para a Classe "Estação Meteorológica" foram descritos os atributos “Id, Nome, Data Início, Hora, Intervalo, Latitude, Longitude, Altitude" e para a Classe "Imagem Radar" foram descritos os atributos "Id, Fonte, Data, Satélite, Resolução, Altitude". Foram estabelecidos, também, os relacionamentos (associações) espaciais e não espaciais entre as classes de objetos, conforme apresentação das figuras 07a e 07b. Na maioria dos relacionamentos foi utilizada a cardinalidade "um para um", de forma subtendida de acordo com o relacionamento das figuras 07 a e $07 \mathrm{~b}$. Em alguns casos a cardinalidade de "muitos para um" foi utilizada. Veja um exemplo na figura 08 , no relacionamento entre as classes "Velocidade de Vento Sintetizada" e "Velocidade de Vento".

Após a definição das classes primárias fundamentais, foram sendo produzidas as classes secundárias, derivadas seja da associação simples ou espacial, bem como de operações. Veja exemplos das classes derivadas "Velocidade de Vento Sintetizada" e "Uso e Ocupação do Solo", bem como a descrição de atributos e operações nas figuras 07a e 07b.

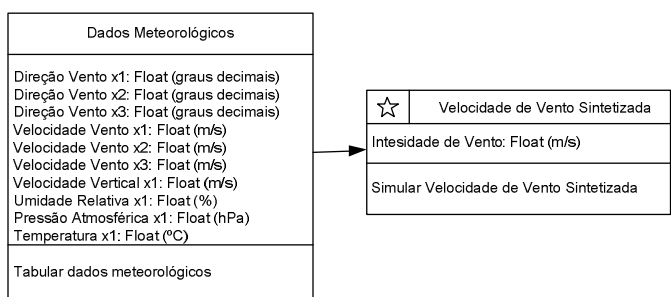

Figura 07a - Classe Primária, Associação Simples e Classe Derivada, com descrição de atributos e operações.

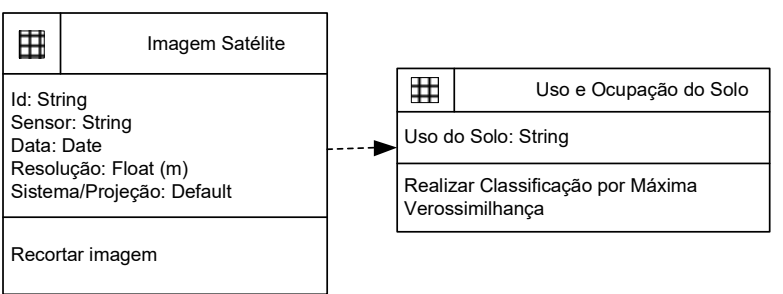

Figura 07b - Classe Primária, Associação Espacial e Classe Derivada, com descrição de atributos e operações.

Para a modelagem dos dados meteorológicos e simulação da velocidade de vento sintetizada foi utilizado o software Windographer, descrito no item 3.5. Somente uma 
operação é demandada pelo software "Extrapolação de janela vertical", onde é possível inserir a altura que se deseja simular. O software retorna valores unitários (por ponto) de velocidade sintetizada na altura inserida de forma convencional. No modelo conceitual tal operação foi descrita como "Simular Velocidade de Vento Sintetizada", conforme exemplo apresentado na figura 07a da classe "Velocidade de Vento Sintetizada".

Para utilização dos dados meteorológicos no software Windografer, primeiramente devem ser estruturados no ambiente Excel as colunas com os dados meteorológicos fundamentais para gerar a curva logarítmica que simula a velocidade de vento em grandes alturas, com data e horário de início das medições, a altitude da estação $(\mathrm{m})$, bem como o período em minutos. Geralmente são simuladas velocidades de vento em 80 m, 100 m e 150 m (altura padrão dos aerogeradores), conforme descrições do capítulo 03. No modelo conceitual tal operação foi descrita como "Tabular Dados Meteorológicos", conforme exemplo apresentado na figura 07a da classe "Dados Meteorológicos".

Para transformar a informação convencional para geográfica, da classe "Dados Meteorológicos" os valores unitários advindos do Windographer foram transformados em um único arquivo de pontos para a Classe Geográfica "Velocidade de Vento Sintetizada" para ser trabalhada em SIG, através de uma operação de interpolação denominada "Topo to Raster"ou "topográfico para raster" no modelo conceitual, para gerar uma subclasse "Velocidade de Vento" na visão de campo Tesselação. Para esta etapa e todas as demais que necessitavam de SIG foi utilizado o ArcGIS 10.2. Veja o exemplo desta transformação na Figura 08.

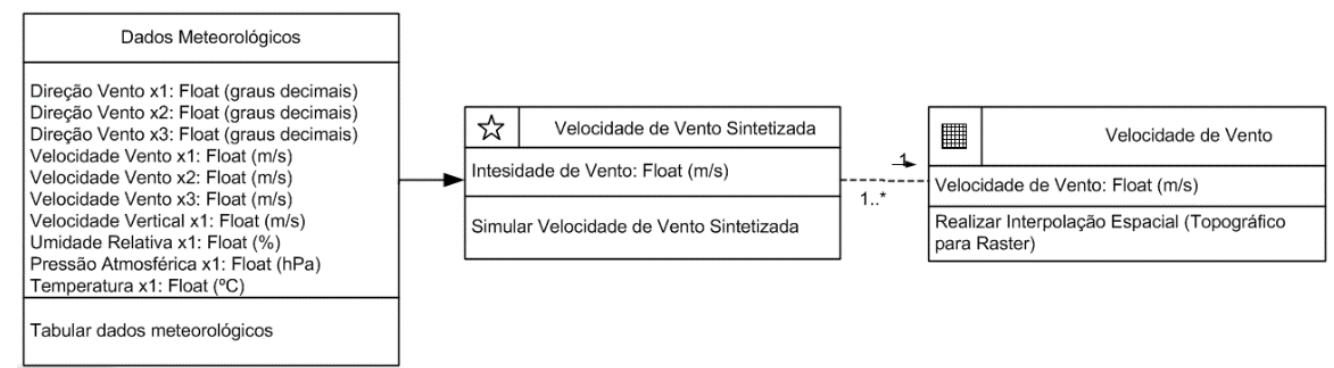

Figura 08 - Classe Primária, Associação Simples e Classe Derivada, com descrição de atributos e operações.

Com exceção da modelagem eólica e de algumas ferramentas que funcionam fora do Toolbox do ArcGIS (como a Classificação Supervisionada, por exemplo), todas as demais 
operações definidas na modelagem conceitual foram implementadas no Model Builder do ArcGIS 10.2 para validar o método proposto de forma lógica e física.

A modelagem conceitual, por ser muito complexa, está sendo apresentada, seccionada em grupos temáticos de energia, a saber, por geração solar, eólica e hídrica, conforme apresentação das figuras 09, 10 e 11, respectivamente, onde podem ser visualizadas as classes modeladas, bem como seus atributos, operações e relacionamentos.

Já o Modelo conceitual para identificação de áreas com potencial para gerar energia por fonte renovável (esquema na íntegra) pode ser observado na figura 12, onde pode ser observada a classe resultante "Potencial Solar, Eólico e Hídrico", gerada através de operações das classes "Indicação Solar", "Indicação Eólica" e "Lâmina Dágua" advindas dos três modelos apresentados nas figuras 09, 10 e 11.

É importante ressaltar que algumas classes são fundamentais para a produção de todos os modelos, por isso elas aparecem como classes primárias e derivadas em todos os modelos apresentados. Exemplo disto é a classe "Declividade", gerada por operação da classe "DEM", que por sua vez é derivada da classe primária "Imagem Radar". Outro exemplo é a classe "Uso do Solo Classificado", derivada por reclassificação da classe "Uso e Ocupação do Solo", que foi, através de classificação supervisionada, gerada a partir da classe primária "Imagem Satélite".

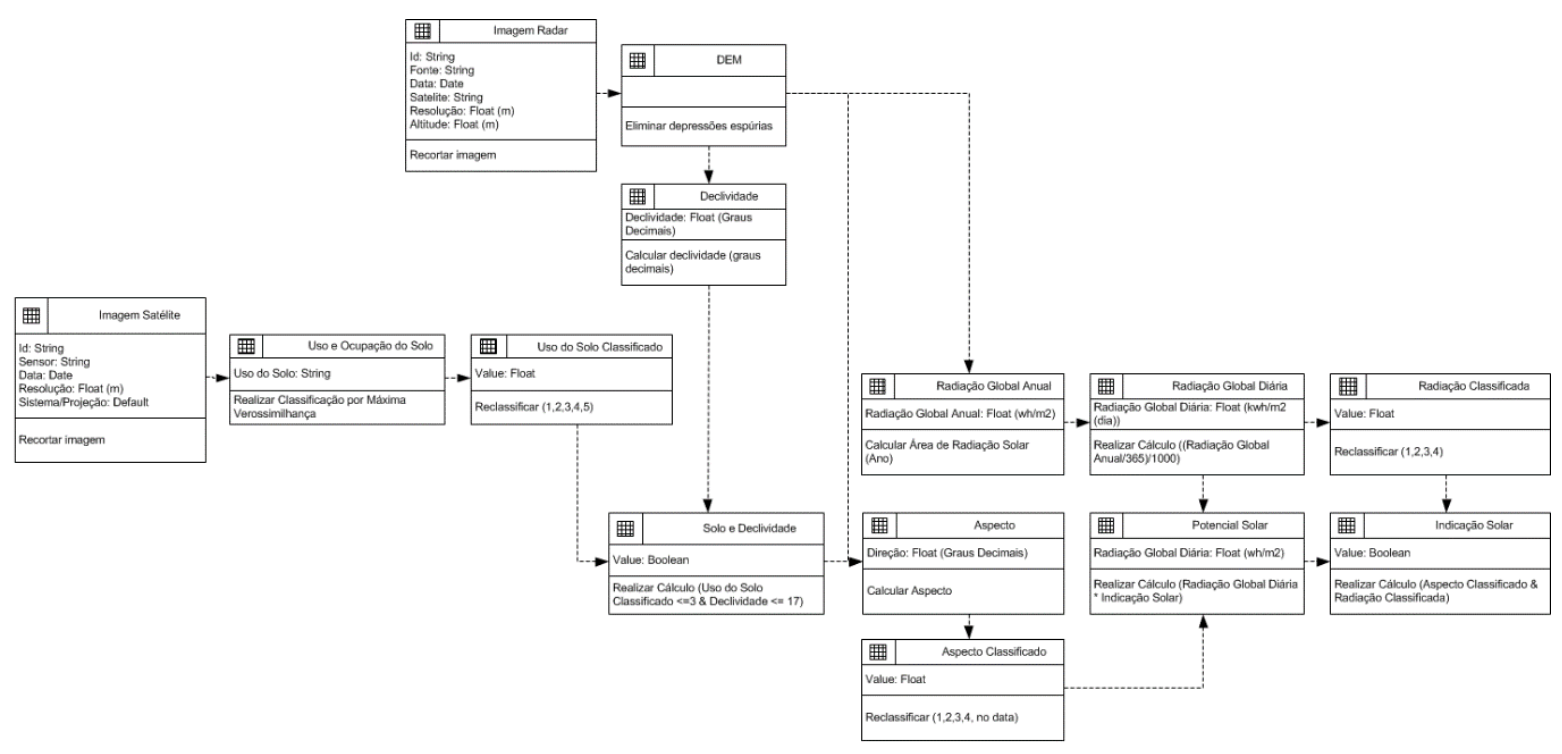

Figura 09 - Modelagem Conceitual Geração Solar 


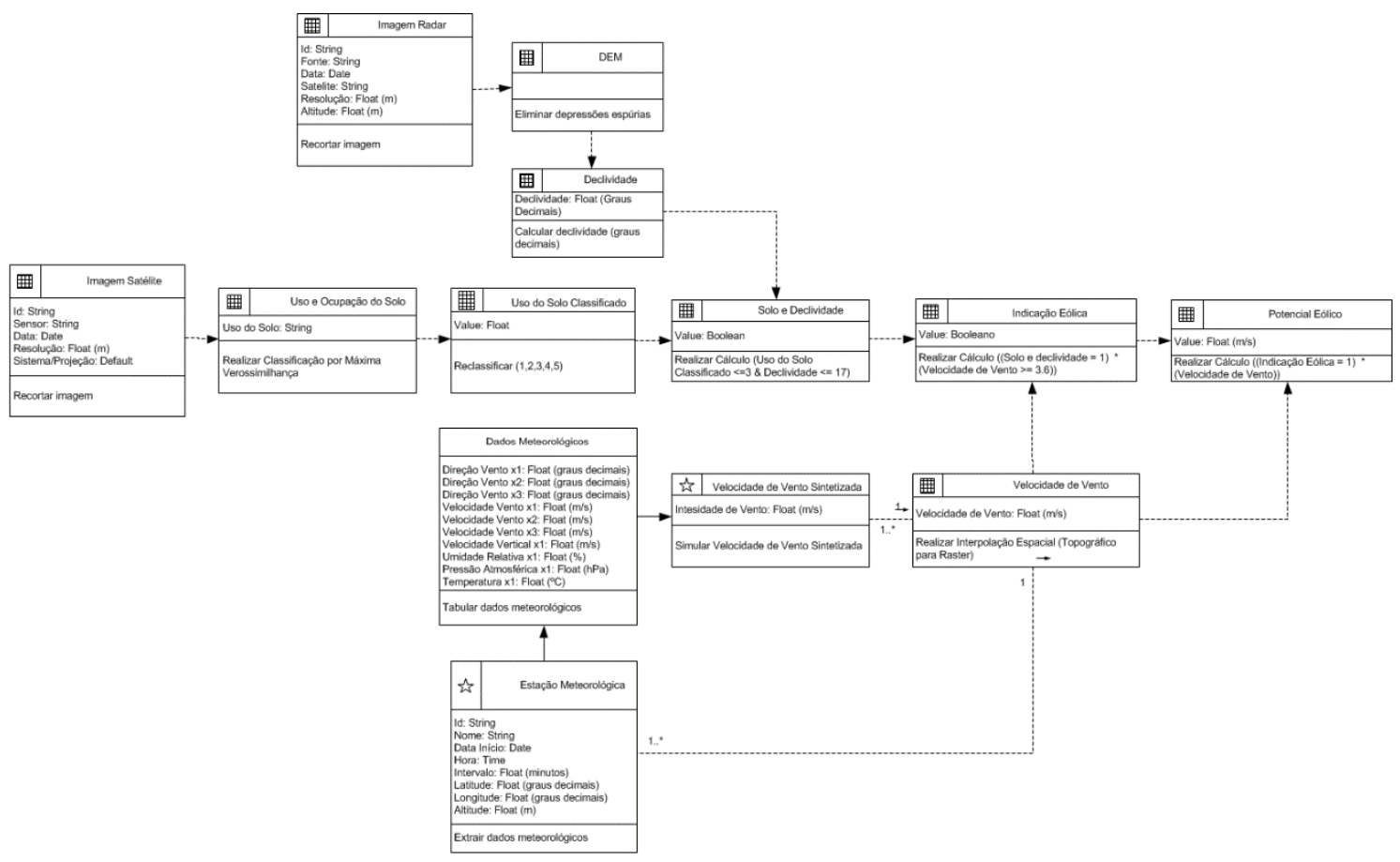

Figura 10 - Modelagem Conceitual Geração Eólica

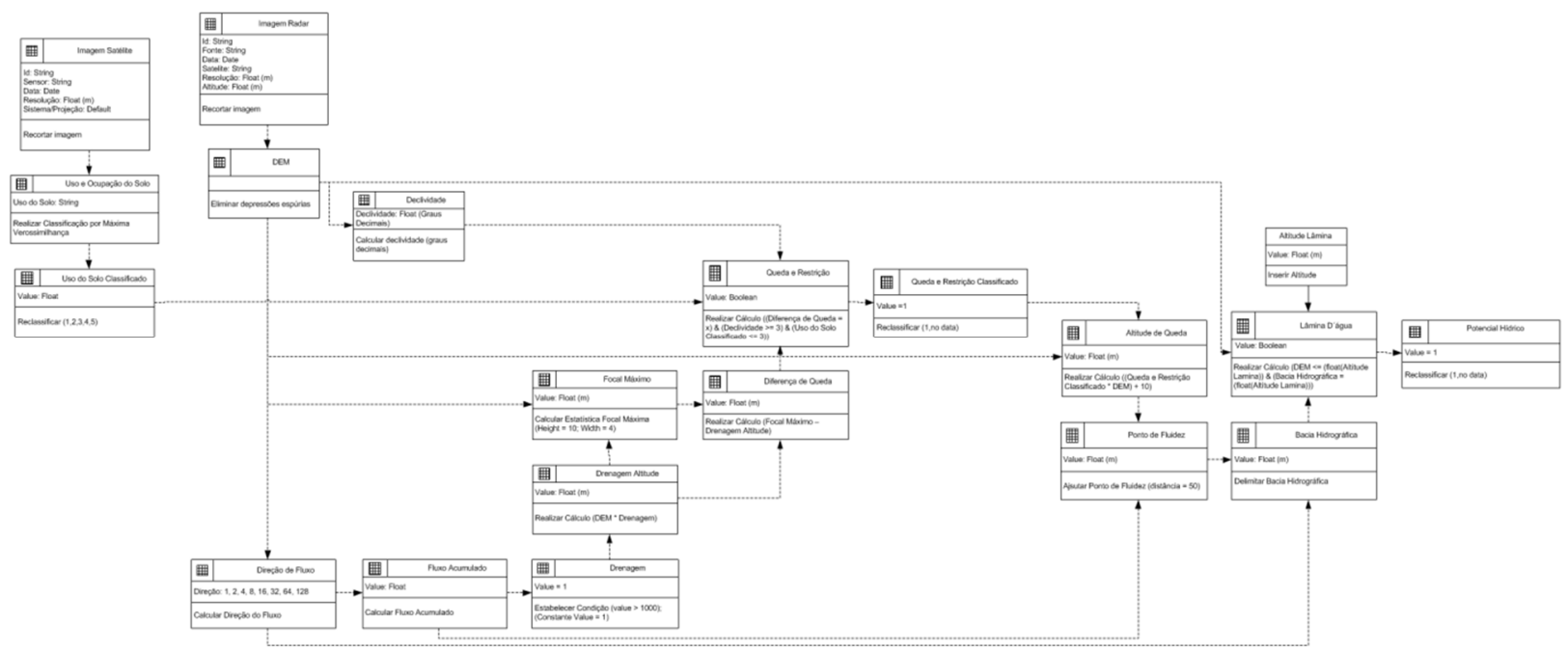

Figura 11 - Modelagem Conceitual Geração Hídrica

Não é objetivo deste trabalho realizar a apresentação do modelo físico em Model Builder (ArcGIS 10.2), bem como dos mapas gerados a partir desta implementação, pois o modelo conceitual apresentado pode ser aplicado em qualquer software de SIG. 


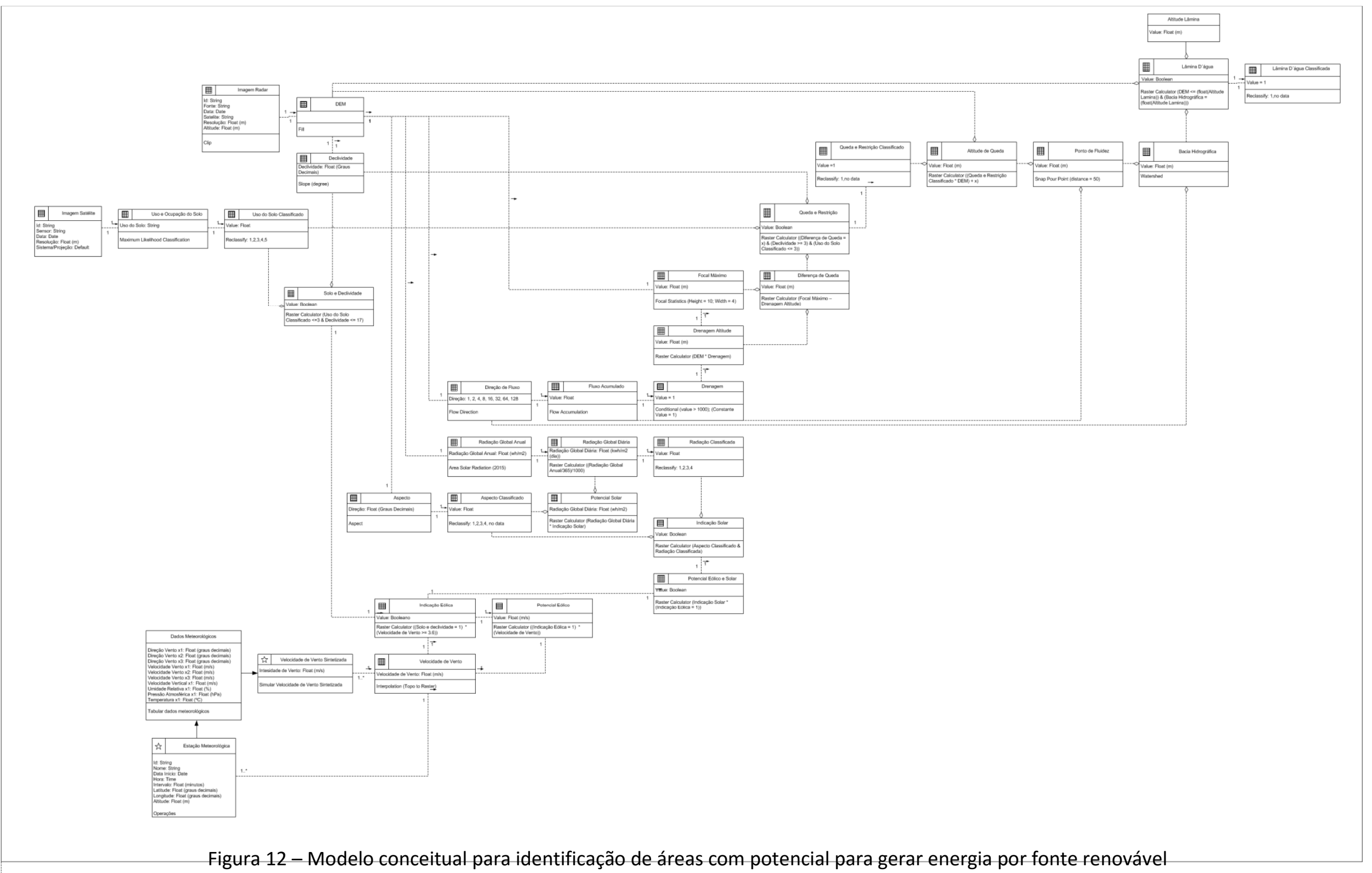




\section{Conclusões}

Conclui-se com este trabalho que o objetivo principal foi cumprido, tendo em vista que foi proposto um modelo conceitual para identificação espacial de áreas que possuem potencial de geração de energia elétrica por até três fontes de energias renováveis, seja hídrica de pequeno formato, eólica ou solar (fotovoltaico e térmico). O método proposto foi aplicado fisicamente em Model Builder para validação e apresentou resultados satisfatórios.

Conclui-se também que foram indicados produtos fundamentais, que são disponibilizados gratuitamente na Internet, para realizar o mapeamento de áreas com potencial para gerar energia elétrica pelas fontes renováveis definidas, bem como quais os níveis de informação são extraídos deles.

O principal resultado, apresentado na figura 12 (Modelo Conceitual para identificação de áreas com potencial para gerar energia por fonte renovável) é considerado de aplicação universal e pode ser reaplicado em qualquer software de SIG e em qualquer área geográfica.

\section{Considerações Finais}

Este artigo apresenta o resultado da primeira etapa de uma pesquisa de pós-doutoramento ocorrida entre os meses de março de 2015 e novembro de 2015, realizada em Portugal na Universidade Nova de Lisboa. Para maiores detalhes sobre toda a investigação favor contatar os autores. A bolsa de pós-doutoramento foi financiada pelo Conselho Nacional de Desenvolvimento Científico e Tecnológico (CNPQ) do Brasil.

\section{Referências Bibliográficas}

AGENCIA NACIONAL DE ENERGIA ELÉTRICA - ANEEL. Atlas de energia elétrica do Brasil. 3a edição. Brasília: ANEEL, 2008. 236p.

AMARANTE, O. A. C.; SILVA, F. J. L.; ANDRADE, P. E. P. Atlas Eólico: Espírito Santo. Agência de Serviços Públicos de Energia do Estado do Espírito Santo (ASPE). Vitória/ES. 2009. 100p. 
AWS TRUEPOWER LLC, 2015. Disponível em https://www.windographer.com.

BORGES, K. A. V.; DAVIS JÚNIOR, C. A.; LAENDER, A. H. F. 2005. Modelagem conceitual de dados geográficos. In: CASANOVA, et. al. Banco de Dados Geográfico. MundoGEO: Curitiba, 2005. Cap. 1, p. 83-136.

BORGES, K. A.V. Modelagem de banco de dados geográficos. Apostila do Curso de Especialização em Geoprocessamento. Universidade Federal de Minas Gerais, Belo Horizonte. 2002.

BORGES, K. A.V. Modelagem de dados geográficos: uma extensão do modelo OMT para aplicações geográficas. 1997. 139 f. Dissertação (Mestrado em Administração Pública) - Escola de Governo, Fundação João Pinheiro, Belo Horizonte. 1997.

BORGES, K.A.V; DAVIS, C. Modelagem de Dados Geográficos. IN: Câmara, G.; Davis, C.; Monteiro, A. M. V.; (Org). Introdução à Ciência da Geoinformação. INPE, São José dos Campos: São Paulo, 2001. Disponível em www.dpi.inpe.br/gilberto/livro/introd/cap4-modelos.pdf.

BRITISH PETROLEUM. QUANTIFYING ENERGY. BP Statistical Review of World Energy. 2006. Disponível em http://www.bp.com.

COSME, A. Projeto em Sistemas de Informação Geográfica. Lidel - edições técnicas, Ida. Lisboa. 2012. 366p.

CRAVEIRO, G. K. C. Metodologia para implementação de um Sistema de Informações Geográficas para ambiente urbano. 2004. 194f. Dissertação (Mestrado em Ciências em Engenharia de Transporte) - Curso de Pós Graduação de Engenharia, COPPE, Universidade Federal do Rio de Janeiro, Rio de Janeiro. 2004.

ELOY, A. Energias Sem-fim - Contrariando as Alterações Climáticas. Edições Colibri. Lisboa. 2009. 124p.

HUBNER, C. E. Proposta de gestão de dados cadastrais para gestão sociopatrimonial de empreendimentos de geração de energia hidrelétrica em fase de implantação. 2009. 339 f. Dissertação (Mestrado em Engenharia Civil) - Programa de Pós Graduação em Engenharia Civil, Universidade Federal de Santa Catarina, Florianópolis. 2009.

INTERNATIONAL ENERGY AGENCY - IEA, 2009. Wind Technology Roadmap. International Energy Agency. Disponível em www.eia.org/Papers/2009/wind_roadmap.pdf.

JUANA, J. M. Energias Renováveis para o Desenvolvimento. Editorial Thomson Paraninfo. 2003.

LINARD, F. J. A. Estimativas da velocidade do vento em altitude usando o Software Windographer. Monografia. (Monografia de Graduação em Bacharelado em Física) Centro de Ciências e Tecnologia, Universidade Estadual do Ceará, Fortaleza, 2010.

LISBOA FILHO, J. et al. Modelagem conceitual de banco de dados geográficos: o estudo de caso do projeto PADCT/CIAMB. In: Carvão e Meio Ambiente. Porto Alegre: UFRGS, 2000. p. 440-458.

LISBOA FILHO, J; IOCHPE, C. Um estudo sobre modelos conceituais de dados para projeto de bancos de dados geográficos. Revista Informática Pública, Belo Horizonte, v.1, n.2. 1999b. p. 67-90.

MENDES, P. G. Desenvolvimento de uma aplicação SIG no apoio à gestão da rega: o caso de estudo do Alentejo (Portugal). Dissertação (Mestrado em Sistemas de Informação Geográfica) - Departamento de Engenharia Geográfica, Geofísica e Energia, Universidade de Lisboa, Lisboa. 2013.

ORGANIZAÇÃO DAS NAÇÕES UNIDAS PARA O DESENVOLVIMENTO INDUSTRIAL (ONUDI) - OBSERVATÓRIO DE ENERGIAS RENOVÁVEIS PARA A AMÉRICA LATINA E O CARIBE - Energia e Mudança Climática. Programa de Capacitação em Energias Renováveis. 2013.

QUEIROZ, G. R; FERREIRA, K. R. Tutorial sobre Bancos de Dados Geográficos. Geográficos. GeoBrasil, 2006. Anais... São José dos Campos: INPE, 2006. 104 p.

SILVA, V. C. B. Criando um Model Builder no ArcGIS. Guest Post. Belo Horizonte. 2015. 